\title{
IMPLICAÇÕES DA IMUNOCASTRAÇÃO NA NUTRIÇÃO DE SUÍNOS E NAS CARACTERÍSTICAS DE CARCAÇA
}

\author{
IMPLICATIONS OF THE IMMUNOCASTRATION ON SWINE NUTRITION \\ AND CARCASS TRAITS
}

\author{
Martins, P.C. ${ }^{1 *}$; Albuquerque, M.P. de ${ }^{1}$; Machado, I.P. ${ }^{1}$ e Mesquita, A.A. ${ }^{2}$ \\ ${ }^{1}$ Universidade Federal de Goiás (UFG). Jataí, GO. Brasil. *polianamartinsvet@hotmail.com \\ ${ }^{2}$ Universidade de Rio Verde (FESURV). Rio Verde, GO. Brasil.
}

PaLAVRAS ChAVE ADICIONAIS

Deposição de carne magra. GnRH. Ractopamina.

\section{RESUMO}

Na castração imunológica, vacinas contendo um GnRH modificado conjugado a uma proteína induzem a formação de anticorpos direcionados contra o $\mathrm{GnRH}$. O objetivo desta revisão é esclarecer o que é a imunocastração e abordar os principais efeitos desta prática sobre o consumo de ração e exigências nutricionais de suínos. A vacina é capaz de reduzir as concentrações de escatol e androsterona em suínos machos inteiros, diminui a incidência de brigas e tem efeito direto sobre a nutrição destes animais. O macho imunocastrado é uma categoria que se comporta como macho inteiro no início e como macho castrado após a aplicação da segunda dose da vacina, conduzindo à necessidade de adequação das estratégias nutricionais e esta nova realidade. Imunocastrados respondem bem ao aumento dos níveis de lisina na dieta, apresentam maior ganho médio diário de peso, maior rendimento de carcaça e de carne magra e diminuição do toucinho. A ractopamina, um aditivo modificador do metabolismo, tem sido utilizada pelos sistemas intensivos de produção, em associação à castração imunológica, por melhorar o crescimento, aumentar a massa magra e reduzir a deposição de tecido adiposo. São precisos estudos que definam corretamente as exigências nutricionais do imunocastrado, que também possam adequar os níveis nutricionais das dietas contendo ractopamina para esta categoria.

\section{SUMMARY}

In immunological castration, the vaccine

\section{AdDitional KEYWORDS}

GnRH. Lean meat deposition. Ractopamine. containing a modified $\mathrm{GnRH}$ conjugated to a protein induces the formation of antibodies, which are directed against $\mathrm{GnRH}$. The aim of this review is to clarify what is immunocastration and to include the main effects of this practice on feed intake and nutrient requirements of pigs. The vaccine is capable of reducing the concentrations of skatole and androstenone in boars, decreases the incidence of fights and has a direct effect on the nutrition of these animals. The imunocastrated male is a category that behaves like male at first and as barrow after the second dose of the vaccine, leading to the need for adequation of nutritional strategies and this new reality. Immunocastrated respond well to increased levels of lysine in the diet, have greater weight gain, higher carcass yield and lean meat and reduced backfat deposition. The ractopamine, an additive which modifies the metabolism, has been used for intensive production systems, combined with immunological castration, to improve growth, increase lean body mass and reduce fat deposition. Studies are needed to define the real nutritional requirements of imunocastrated, and to adapt the nutrient levels of diets containing ractopamine for this category.

\section{INTRODUÇÃO}

Nos últimos anos, a produção mundial de suínos tem aumentado consideravelmente, na tentativa de atender a demanda da população por fontes de proteína animal, a 
um preço mais acessível.

Neste sentido, técnicas de manejo e procedimentos que venham a otimizar a produção e garantir a qualidade do produto final, aliados a recursos que promovam melhor aproveitamento dos nutrientes pelo organismo animal são cada vez mais pesquisados e aplicados na rotina das granjas de suínos.

Uma dessas práticas é a castração cirúrgica, realizada com o intuito de evitar a presença do odor sexual na carne de suínos machos. Entretanto, por se tratar de um procedimento invasivo, causa estresse e por isso não é bem visto quando se considera o bem estar destes animais, além de prejudicar o desempenho dos mesmos.

Assim, no ano de 1993, pesquisadores australianos passaram a estudar a possibilidade de castração imunológica dos suínos, e logo estudos em diferentes países sobre esta técnica mostraram que a mesma poderia ser empregada, fazendo com que a utilização de uma vacina comercial fosse aceita por agências de saúde e vigilância sanitárias. Dentre os maiores países produtores de carne suína, o primeiro a ter este acordo foi o Brasil (Lovatto et al., 2010).

Lançada em 2007 e testada pelos maiores produtores mundiais de suínos, a imunocastração foi adotada como prática de rotina para os suínos em fase de terminação (Heck, 2011a). Seu princípio consiste na aplicação de vacinas contendo um GnRH modificado conjugado a uma proteína, que induz a formação de anticorpos direcionados contra o GnRH (Zamaratskaia et al., 2008).

Entre os benefícios da imunocastração, estão a maior deposição de carne magra na carcaça e o fato de que os animais não precisam ser submetidos ao estresse provocado pela castração convencional.

Efeitos sobre parâmetros nutricionais, como consumo de ração e conversão alimentar, e maior resposta aos aditivos melhoradores metabolismo animal, tais como a ractopamina, também são relatados.
Diante do exposto, o objetivo desta revisão é esclarecer o que é a imunocastração e abordar os principais efeitos desta prática sobre o consumo de ração e requerimentos nutricionais de suínos.

\section{IMUNOCASTRAÇÃO}

O GnRH é um hormônio produzido no hipotálamo, que tem a função de induzir a produção de gonadotrofinas (LH e FSH) pela hipófise anterior, que por sua vez agem nas gônadas, estimulando o crescimento testicular e a espermatogênese, entre outras funções. Nos testículos, o LH atua na produção de hormônios esteróides, porém alguns destes não possuem função anabolizante, mas resultam no aparecimento do odor e sabor na carcaça em machos após a puberdade (Santos, 2009).

Conforme Dunshea et al. (2001) e Tonietti (2008), suínos em fases peri e pós púbere acumulam substâncias, tais como androsterona e escatol, em seu tecido adiposo, sendo elas responsáveis pelo odor sexual encontrado na carne de machos inteiros.

Este odor é desagradável e provoca a rejeição da carne (Santos, 2009), embora seja interessante mencionar que estudos apontam que a sensibilidade de cada indivíduo ao odor sexual da carne pode refletir em variação na resposta do mercado ao consumo deste produto. Por exemplo, consumidores irlandeses, canadenses, americanos e do Reino Unido aceitarão mais facilmente a carne proveniente de suínos machos inteiros se comparados a consumidores da França, Suécia, Holanda e Espanha (Font et al., 1999).

Enfim, devido ao problema de rejeição da carne, buscam-se alternativas para evitar o aparecimento deste odor e sabor, das quais a castração cirúrgica antes da desmama é o método mais difundido atualmente (Santos, 2009).

Convencionalmente, visando evitar a presença de odor sexual na carne, os leitões 
são submetidos nos primeiros dias de vida a um procedimento cirúrgico para a retirada dos testículos e são denominados como machos castrados cirurgicamente ou somente castrados (Silva et al., 2011).

Entretanto, a castração cirúrgica, por consistir na remoção dos testículos, provoca a eliminação dos hormônios esteróides, impedindo o favorecimento de desempenho, além de ser um procedimento invasivo que causa problemas relacionados ao bem-estar animal (Santos, 2009). Assim, a castração imunológica, surge como alternativa à castração cirúrgica, possibilitando a criação dos animais sem que haja a necessidade de retirada dos testículos, uma vez que o funcionamento do eixo gônadas-hipófisehipotálamo fica bloqueado, reduzindo assim a produção das substâncias responsáveis pelo desenvolvimento do odor sexual (Silva et al., 2011).

Uma das vantagens da imunocastração é a possibilidade de manter a integridade de leitões que seriam cirurgicamente castrados no início da vida (Barbosa et al., 2012). Isto atende aos princípios estabelecidos pela Comissão Européia, especificados na
Directiva 2008/120/CE do Conselho, relativa às normas mínimas de proteção de suínos, segundo a qual deve tomar em consideração o desenvolvimento de técnicas e sistemas de produção de porcos e de transformação dos alimentos que possam diminuir a necessidade de recurso à castração cirúrgica (Comissão Europeia, 2008).

Além da questão de bem-estar animal, esta ferramenta confere benefícios na produção e aumenta o rendimento dos cortes no abatedouro (Heck, 2011a), pois possibilita que, pela ação de vários hormônios, os animais venham a expressar melhor seu potencial de deposição de carne magra nas carcaças, com consequente melhora da conversão alimentar (Silva et al., 2011).

Assemelha-se a qualquer outro processo vacinal, porém se trata de muito mais do que isso (Heck, 2011b). A vacina desenvolvida possui uma forma de GnRH modificado, contida em meio adjuvante aquoso, capaz de causar uma reação tecidual (Dunshea et al., 2001).

A utilização do próprio sistema imune do suíno para suprimir o hormônio interrom-

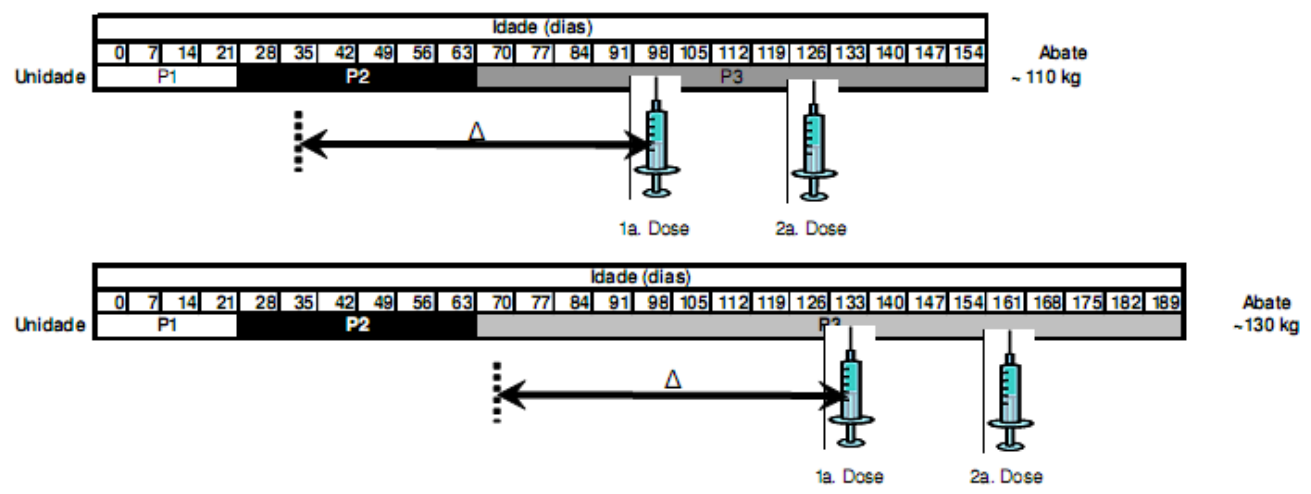

P1: Fase inicial; P2: Fase de crescimento; P3: Fase de terminação.

Figura 1. Protocolo de imunocastração de machos inteiros abatidos aos 110 e $130 \mathrm{~kg}$ de peso vivo. (Immunocastration protocolo of entire males slaughtered at 110 and $130 \mathrm{~kg}$ live weight). (Silva et al., 2011). 
pe o eixo hipotalâmico-hipofisário-gonadal, ao estabelecer uma barreira imunológica que interrompe a passagem do $\mathrm{GnRH}$ do local de liberação no hiotálamo ao local de ação, na glândula pituitária (Martinuzzi et al., 2011). Ao ser suprimido, o GnRH não pode estimular a secreção de LH e FSH pela gandula pituitária, e isto leva a redução do desenvolvimento dos testículos e da síntese de hormônios esteroides (Thun et al., 2006).

Em programas de imunocastração, os machos são considerados imunocastrados somente após o cumprimento de um protocolo de vacinação e de tempo de resposta antes do abate (figura 1), necessários para garantir ausência de odor na carne (Silva et al., 2011).
É possível aplicar a primeira dose do produto na fase de creche e até mesmo na terminação. Esta flexibilidade permite a adaptação das diferentes realidades de estrutura de produção. Não há diferença de desempenho por se escolher diferentes momentos para a aplicação da primeira dose (Heck, 2011b).

A formulação da vacina e o seu protocolo de aplicação permitem que os suínos recebam a segunda dose por volta de quatro a cinco semanas antes do abate. Qualquer substância responsável pelo odor sexual já presente nos tecidos é progressivamente metabolizada, permitindo que o macho inteiro depois de vacinado seja abatido com maior peso corporal e sem odor na carne, após ter

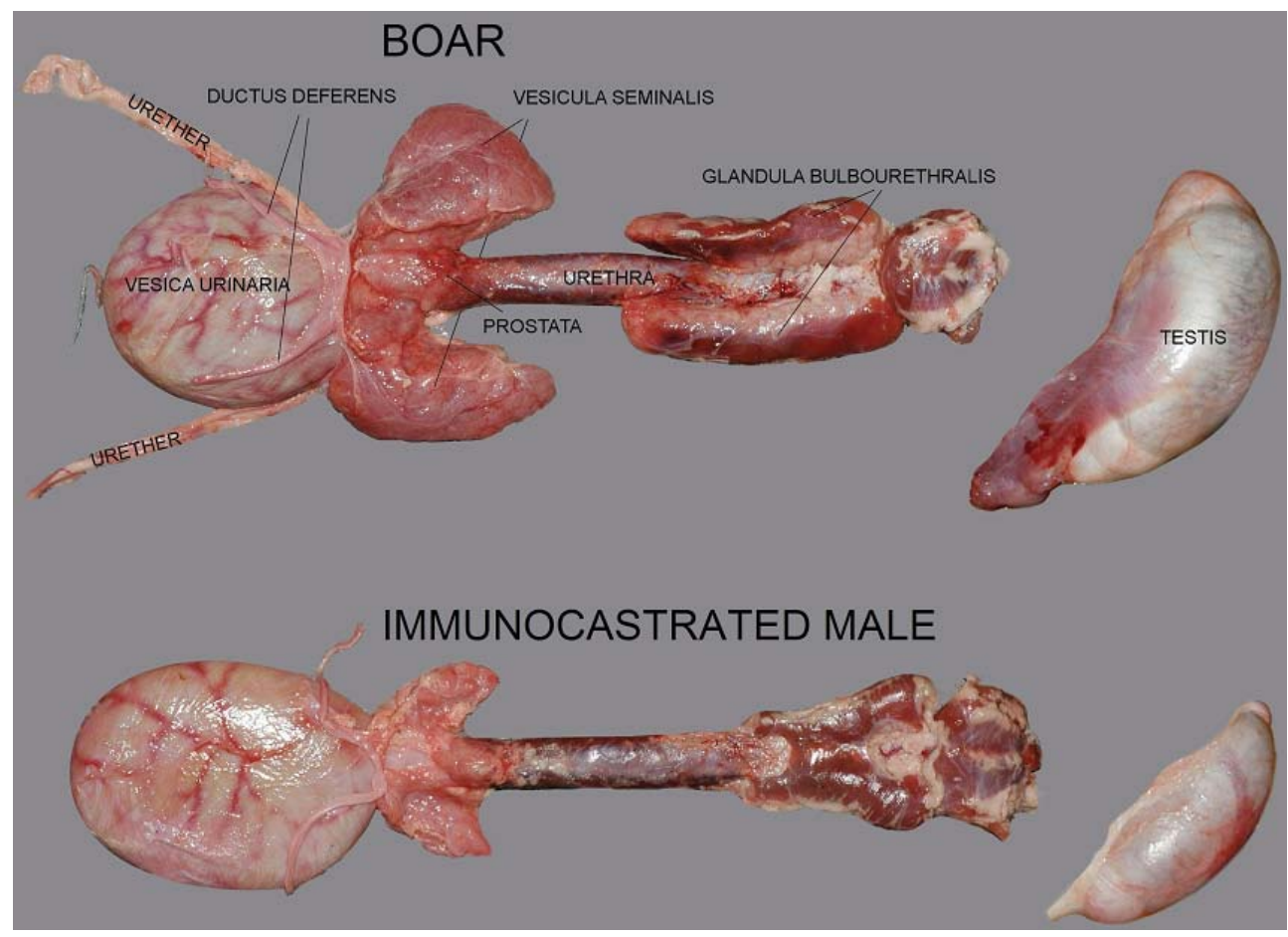

Figura 2. Imagem representativa dos testículos e das glândulas anexas em suíno inteiro vs imunocastrado. (Representative image of the testicles and accessory glands in entire vs immunocastrated pigs).

(Skrlep et al., 2010). 
sido beneficiado com os efeitos de seus próprios esteróides testiculares durante o crescimento (Dunshea et al., 2001).

Na figura 2 são comparados os testículos e as glândulas reprodutoras acessórias do suíno macho interiro e do imunocastrado.

A vacina é eficiente na redução das concentrações de escatol e androsterona, além de elevar o consumo alimentar e o crescimento. Também é verificado um menor número de lesões ao abate provenientes de brigas, em animais vacinados contra o GnRH (Dunshea et al., 2001).

Para se adotar o processo de imunocastração, é necessário estar alerta a uma série de fatores. Deve se considerar desde a legislação ambiental, abatedouro, medicamentos veterinários, estrutura da propriedade, mão-de-obra, rotina de trabalho até o consumidor final (Heck, 2011b).

Além disso, pode-se afirmar que o advento da imunocastração poderia levar à designação de novas funções na linha de abate. Heck(2011b) relata que um funcionário poderia ser responsável por medir e separar machos que possuam tamanho de testículo maior que $110 \mathrm{~mm}$ e realizar o teste de cozimento da gordura dos suínos suspeitos de apresentar odor de macho na carne.

\section{EFEITODAIMUNOCASTRAÇÃO SOBRE O CONSUMO DE RAÇÃO E REQUERIMENTOSNUTRICIONAIS}

O surgimento da tecnologia de imunocastração fez com que os nutricionistas se deparassem, além dos machos inteiros, dos machos cirurgicamente castrados e das fêmeas, com uma quarta categoria - o macho imunocastrado. Este animal se caracteriza por apresentar dois comportamentos distintos: tanto o de macho inteiro quanto o de macho castrado cirurgicamente, que surge após a aplicação da segunda dose da vacina de imunocastração (Silva et al., 2011).

No Brasil, a adoção da técnica de imunocastração aconteceu de forma tão rápida que as estratégias nutricionais e alimentares não acompanharam essa evolução. Na prática, por diferentes razões, os machos inteiros são normalmente alimentados com as mesmas dietas de machos castrados e fêmeas. Sendo o desempenho dos machos inteiros superior, é conveniente realizar a adequação das exigências nutricionais e o manejo alimentar (Porolnik et al., 2009).

A correta definição das exigências nutricionais de machos inteiros submetidos a imunocastração ainda é um tema que necessita de intenso esforço científico, seja pelas variações no consumo diário de nutrientes ou deposição de componentes corporais de acordo com variações no protocolo de vacinação (Silva et al., 2011).

\section{CONSUMO DE RAÇÃO}

As exigências nutricionais de machos imunocastrados se relacionam diretamente ao cumprimento do protocolo de vacinação e manejo alimentar. Sob condições comerciais, é correto afirmar que os machos inteiros apresentam menor consumo de ração e o procedimento de imunocastração influencia sobremaneira esta característica, principalmente após a aplicação da segunda dose da vacina, o que pode afetar as exigências nutricionais e a resposta dos animais às rações e ao programa alimentar (Silva et al., 2011).

Conforme Skrlep et al. (2010), o consumo de ração e a conversão alimentar de machos imunocastrados se assemelham aos de machos inteiros até a administração da segunda dose, quando então nota-se maior semelhança com os cirurgicamente castrados.

Os dados do perfil de consumo ração de machos inteiros submetidos à imunocastração e de machos castrados cirurgicamente, durante as fases de crescimento e de terminação (25 a $130 \mathrm{~kg}$ ) são apresentados na figura 3. Estes dados foram obtidos de vários lotes de animais, em condições de criação comercial e submetidos a um pro- 
grama alimentar de cinco fases (Silva et al., 2011).

Na figura 3, Silva et al. (2011) destacam a marcante diferença de consumo de ração de animais inteiros e cirurgicamente castrados, até os 145-150 dias de idade, ocasião em que foi aplicada a segunda dose da vacina de imunocastração. Por volta de 10 a 15 dias após a aplicação da segunda dose, os animais imunocastrados passam a ter apetite aumentado e maior consumo de ração. O menor apetite apresentado pelos machos inteiros de 25 a $55 \mathrm{~kg}$ e o maior apetite apresentado após a aplicação da segunda dose da vacina de imunocastração são relevantes no estabelecimento do perfil nutricional das rações e do programa alimentar.

Para melhorar o ganho de peso e aproveitar o potencial de conversão alimentar dos machos inteiros, é necessário estimular o consumo de ração destes animais, no período de 60 a 150 dias de idade. Portanto, qualquer nível de restrição alimentar nesta fase comprometerá o ganho de peso e a conversão alimentar ao abate, pois mesmo havendo aumento de consumo após a segunda vacinação e consequente aumento do ganho de peso, maior será o número de dias necessários para alcançar o peso de abate desejado, comprometendo o resultado econômico da imunocastração (Silva et al., 2011).

Silva et al. (2011) atentam para o fato de que, embora os níveis de odor sexual, tamanho de testículo e a resposta imune contra GnRH não sejam alterados significativamente após a aplicação da primeira dose da vacina, a mudança que ocorre no comportamento alimentar indica que é preferível retardar a aplicação da vacina o máximo possível, com vistas a manter a maior diferença possível na conversão alimentar, conforme mostrado na figura 2. Assim, a melhor premissa é que o consumo diário de ração de machos inteiros é inferior ao de fêmeas e de machos castrados, até 1015 dias após a aplicação da segunda dose da vacina, de modo que o nível de nutrientes na formulação deve ser maior.

Pauly et al. (2009) encontraram nos animais imunocastrados consumo de ração e conversão alimentar semelhantes aos valores apresentados por machos inteiros, sendo estes valores menores do que os encontrados nos machos castrados, indicando melhor eficiência no aproveitamento de nutrientes, além de ganho de peso diário maior do que os machos castrados cirurgicamente, demonstrado principalmente no período final da fase de terminação.

De acordo com estudos de Santos et al. (2012), os animais imunocastrados apresentam ganho de peso diário aproximadamente 8,3\% superior aos castrados. Esta superioridade na fase de terminação tardia pode ser considerada como um indicativo de exigências nutricionais diferenciadas para estas categorias.

Para Santos et al. (2012), a restrição alimentar resulta em melhor conversão alimentar para os suínos machos castrados em relação aos imunocastrados, porém piora o ganho de peso e não altera as características de carcaça dos suínos machos castrados e imunocastrados. Todavia, em ensaios conduzidos por estes pesquisadores, suínos imunocastrados apresentaram melhor conversão alimentar em relação aos castrados, independente do manejo alimentar ao qual foram submetidos. Isto significa que os imunocastrados foram mais eficientes na utilização dos nutrientes da dieta, mesmo após a segunda dose da imunização. Uma provável razão para esse resultado pode ser a existência temporária do efeito residual da produção endógena de hormônios anabólicos nos suínos imunocastrados.

\section{AMINOÁCIDOS}

Como mencionado anteriormente, a vacina para imunocastração obteve uma ótima receptividade dos produtores brasileiros. O interesse dos suinocultures na utilização da vacina imunológica está no 
fato dos machos inteiros apresentarem melhor desempenho em relação aos machos castrados. Isto ocorre porque o potencial genético para deposição protéica de machos inteiros é superior ao de machos castrados e fêmeas (Porolnik et al., 2009).

Para Kiefer et al. (2011), suínos machos imunocastrados apresentam metabolismo diferenciado em relação aos machos castrados e às fêmeas, fato este que pode causar mudanças também de suas exigências nutricionais, principalmente de proteína.

A maior deposição de músculo na carcaça de machos inteiros, se comparados aos machos castrados e às fêmeas, faz com que as exigências nutricionais desta categoria, sobretudo em energia e aminoácidos, sejam superiores. Dessa forma, as dietas para essa categoria animal devem ser nutricionalmente mais densas, para atender as exigências alimentares desses animais (Zaltron et al., 2009).
Este cenário aponta a necessidade de se estudar, por exemplo, a viabilidade econômica das respostas de machos castrados e inteiros com um aporte suplementar em aminoácidos (Zaltron et al., 2009).

Torna-se necessário revisar e estabelecer exigências nutricionais específicas para estes animais. Dentre as exigências de nutrientes a serem reavaliados, podem-se destacar as de lisina digestível, energia, metabolizável ou líquida, cálcio e fósforo, além das relações ideais de aminoácidos. Tem sido dada atenção especial às exigências de lisina e de energia, por conta de seus impactos sobre o desempenho zootécnico, a deposição de carne magra e os custos de produção (Silva et al., 2011).

O genótipo e a castração, cada um à sua maneira, são capazes de afetar a relação entre o consumo energético e a deposição de proteína e, consequentemente, o desempenho de crescimento e a composição

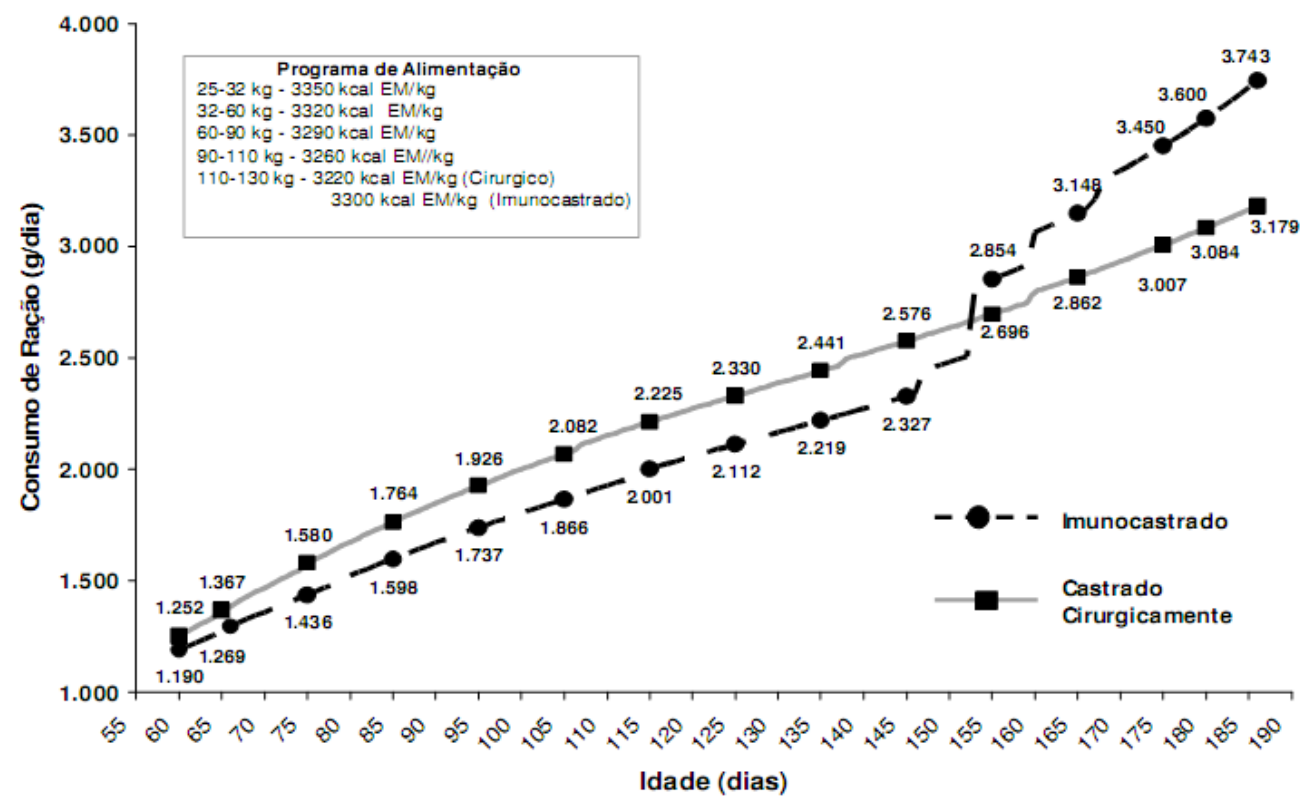

Figura 3. Perfil do consumo de ração de machos castrados cirurgicamente e imunocastrados (dados de campo). (Feed intake profile of castrated and immunocastrated males - field data). (Silva et al., 2011). 
corporal. Experimentos demonstraram que a taxa de deposição de proteína em castrados convencionalmente aumenta linearmente com o aumento da ingestão energética, embora esses mesmos estudos demonstrem que a ingestão ad libitum de ração pode diminuir essa taxa (Campbell e Taverner, 1988).

Quando comparados aos suínos machos castrados, os machos inteiros apresentam menor consumo de ração, mesmo ganho de peso e melhor conversão alimentar. Desta maneira, a alimentação de suínos machos inteiros exige uma suplementação em aminoácidos e energia, suplementação esta que deve ser definida pelo potencial genético e pelas exigências nutricionais utilizadas como referências para formulação das dietas (Lovato et al., 2010).

Estudos prévios compararam machos imunocastrados com aqueles castrados cirurgicamente ou ainda com machos inteiros, recebendo a mesma dieta e com a mesma quantidade de lisina. Em um típico sistema de produção de imunocastrados, os suínos são fisiologicamente inteiros durante grande parte de suas vidas, tornando-se efetivamente castrados apenas após a imunização. Entretanto, as exigências de lisina para suínos inteiros e imunocastrados em condições comerciais precisam ser definidas (Boler et al., 2011).

Quando machos imunocastrados foram alimentados com altos teores de lisina na dieta, o rendimento de cortes de carcaça foi $2,5 \%$ maior do que os valores encontrados para castrados cirurgicamente, sem apresentar efeitos negativos sobre as variáveis de qualidade da carne, tais como maciez, capacidade de retenção de água, $\mathrm{pH}$ final e cor (Boler et al., 2011).

Boler et al. (2011) observaram em seus estudos que o rendimento de carne magra e de carcaça foram maiores em imunocastrados do que em castrados cirurgicamente, mas foram menores do que em machos inteiros. $\mathrm{O}$ aumento da lisina da dieta elevou o rendimento dos cortes, sugerindo que machos imunocastrados devem ser alimentados com dietas contendo maiores níveis de lisina do que cirurgicamente castrados para aumentar o rendimento dos cortes de carcaça. O aumento da lisina na dieta de imunocastrados leva à diminuição do toucinho e aumento da porcentagem de carne magra.

Silva et al. (2011), desenvolveram uma equação de regressão linear que relaciona o peso corporal e a exigência percentual de lisina digestível/Mcal de EM (figura 4), considerando o coeficiente de digestibilidade da lisina igual a 0,90 , a relação EM:ED igual a 0,96 e a relação EL:ED igual a 0,65. Observa-se que, à medida que ocorre o aumento do peso, há queda na exigência de lisina.

Silva et al. (2011) sugere exigências de 0,362, 0,329, 0,276 e 0,229 \% de lisina digestível por Mcal de EM, respectivamente para as fases de 25 a 35, 35 a 60, 60 a 90 e 90 a $110 \mathrm{~kg}$ de peso vivo, para animais que não receberam a segunda dose da vacina. Após a segunda vacinação, o potencial de consumo apresentado nesta fase deve ser explorado, o que pode ser feito tanto com o uso de matérias-primas menos palatáveis e de menor custo quanto o uso de modificadores do metabolismo associado aos adequados níveis nutricionais. A importância da vacinação no aproveitamento deste tipo de matéria-prima, tais como o farelo de glúten, a farinha de sangue e a farinha de peixe, reside no fato de que a inclusão de ingredientes não-palatáveis na dieta pode diminuir a ingestão voluntária de ração (Eskinazi, 2011).

Os aditivos modificadores do metabolismo animal podem alterar as taxas de deposição protéica, modificar a proporção da proteína em relação a gordura, alterar o perfil de ácidos graxos na carne ou alterar o metabolismo post mortem (Rossi, 2010). Alguns modificadores metabólicos são compostos por vitaminas, metabólitos vita- 
mínicos (Lawrence e Coppack, 2000) e compostos semelhantes a vitamina, que fornecem benefícios adicionais a carcaça quando adicionados além das exigências dos animais (Heo et al., 2000).

Além disso, têm sido utilizados como aditivos modificadores do metabolismo animal, os agonistas beta-adrenérgicos, com destaque para a ractopamina (Schinckel et al., 2003). Outro exemplo é a somatotropina suína de origem recombinate (STp), um composto utilizado durante as fases de crescimento e terminação, permitindo uma diferente proporção de deposição de tecidos na carcaça (Zuluaga et al., 2007).

Kiefer et al. (2011) testaram quatro pla- nos nutricionais de lisina digestível para machos imunocastrados $(0,9-0,8-0,7 ; 1,0$ 0,9-0,8; 1,1-1,0-0,9 e 1,2-1,1-1,0\%, respectivamente, nas fases dos 67 aos 107 dias, dos 108 aos 135 dias e dos 136 aos 165 dias) e um plano nutricional para machos castrados (constituído pelos níveis de 1,1-1,0-0,9 $\%$ de lisina digestível para as mesmas fases). Os resultados são apresentados na tabela I.

Planos nutricionais com fornecimento de lisina digestível na sequência de 1,1-1,0$0,9 \%$, respectivamente, dos 67 aos 107 dias, dos 108 aos 135 dias e dos 136 aos 165 dias atendem às necessidades nutricionais de suínos machos imunocastrados aos 107 e

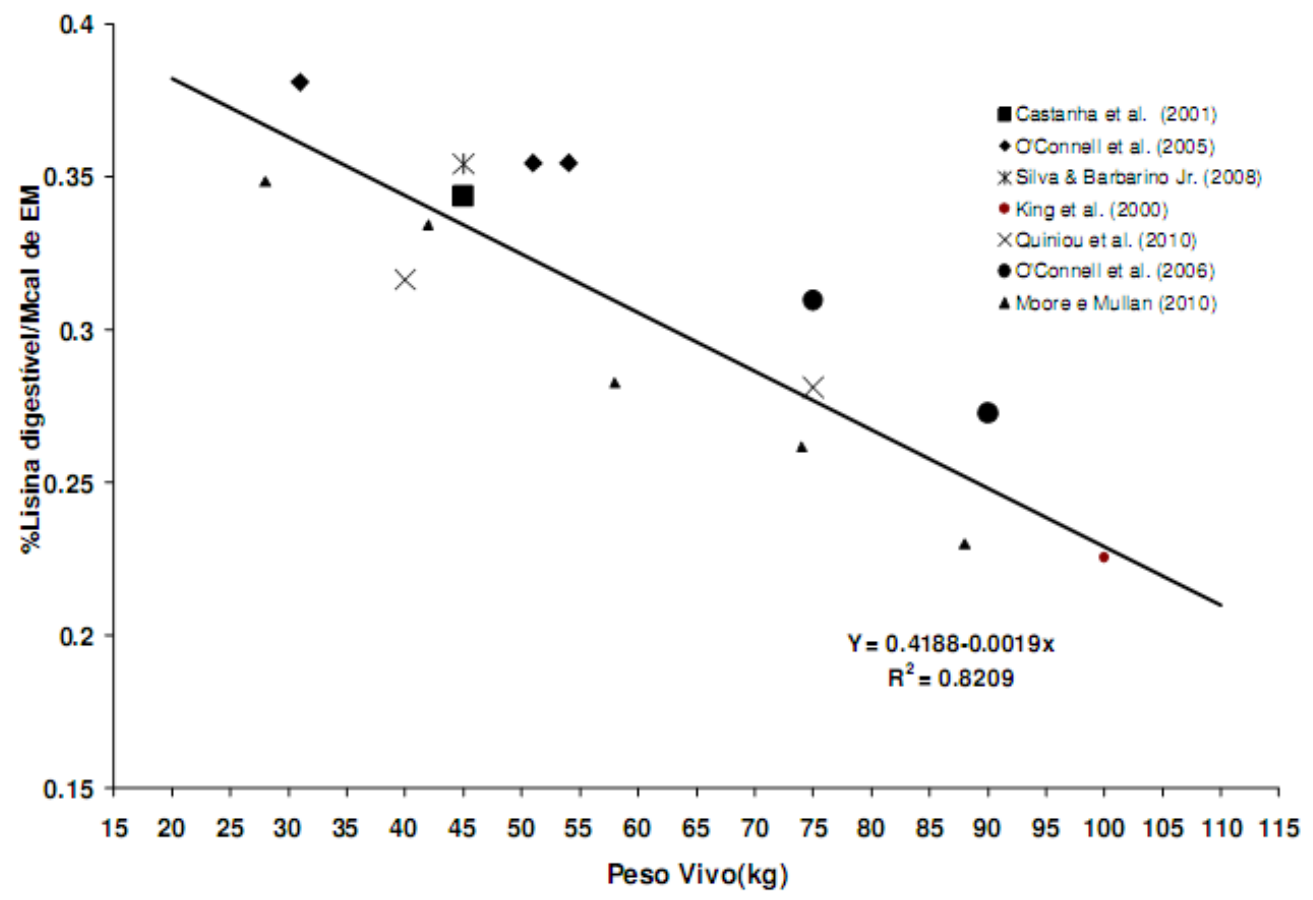

Figura 4. Exigência de lisina digestível, em \%Mcal de EM, em função do peso, para machos inteiros não submetidos à segunda dose da vacina para castração imunológica. (Digestible lysine requirement in Mcal\%, depending on the weight for entire males not subjected to the second dose of vaccine for immunological castration).

(Silva et al., 2011). 
aos 135 dias de idade. Além disso, este plano também é considerado o mais adequado para suínos machos imunocastrados dos 67 aos 165 dias de idade, quando se trata de conversão alimentar, espessura de toucinho e quantidade de carne magra (tabela 1) (Kiefer et al., 2011).

Para Kiefer et al. (2011), a melhora na eficiência de utilização do alimento, indicada pela melhor conversão alimentar, pode ser um indicativo de que ocorreu variação na composição do ganho, com aumento na deposição de proteína e redução na de gordura.

A partir dos resultados obtidos, é possível inferir que suínos machos imunocastrados apresentam desempenho e características de carcaça superiores em comparação aos castrados, implicando em aumento da exigência em aminoácidos na dieta (Kiefer et al., 2011).
Outras observações importantes, desta vez relacionadas à lucratividade do procedimento podem ser encontradas em estudo desenvolvido por Bruno et al. (2013), no qual suínos imunocastrados apresentam menor consumo de ração e melhor conversão alimentar nas fases de crescimento em relação aos castrados cirurgicamente, enquanto na fase de terminação imunocastrados apresentam melhor ganho de peso, conversão alimentar, rendimento e carcaça e porcentagem de carne quando comparados aos castrados por cirurgia. Dessa forma, a utilização de imunocastrados aumenta a lucratividade na produção de suínos, tendo em vista que a análise de lucratividade entre suínos IM e MC deve considerar todas as fases de criação, uma vez que o desempenho diferencial dos suínos não castrados na fase de crescimento inûuencia economicamente os resultados

Tabela I. Conversão alimentar, carne magra $(\mathrm{kg})$ e espessura de toucinho $(\mathrm{mm})$ de suínos machos imunocastrados e castrados em função dos planos nutricionais. (Feed conversion, lean meat $(\mathrm{kg})$ and backfat thickness $(\mathrm{mm})$ of immunocastrated and castrated male pigs according to the nutritional plans).

\begin{tabular}{|c|c|c|c|c|c|}
\hline & $\begin{array}{c}\text { Plano } \\
\text { nutricional }\end{array}$ & $\begin{array}{l}\text { Peso } \\
\text { final }\end{array}$ & $\begin{array}{l}\text { Conversão } \\
\text { alimentar }\end{array}$ & $\begin{array}{c}\text { Carne } \\
\text { magra }(k g)\end{array}$ & $\begin{array}{l}\text { Espessura de } \\
\text { toucinho }(\mathrm{mm})\end{array}$ \\
\hline \multicolumn{6}{|l|}{ Categoria } \\
\hline Machos imunocastrados (1) & $0,9-0,8-0,7$ & 118,58 & $2,52^{\mathrm{a}}$ & $56,7^{b}$ & $11,63^{a}$ \\
\hline Machos imunocastrados (2) & $1,0-0,9-0,8$ & 118,17 & $2,48^{a}$ & $55,6^{b}$ & $9,50^{\mathrm{a}}$ \\
\hline Machos imunocastrados (3) & $1,1-1,0-0,9$ & 119,93 & $2,34^{b}$ & $57,2^{\mathrm{a}}$ & $8,38^{b}$ \\
\hline Machos imunocastrados (4) & $1,2-1,1-1,0$ & 117,12 & $2,44^{\mathrm{a}}$ & $56,9^{b}$ & $9,56^{\mathrm{a}}$ \\
\hline Machos castrados (5) & $1,1-1,0-0,9$ & 113,70 & 2,63 & 53,9 & 10,93 \\
\hline \multicolumn{6}{|c|}{ Probabilidade de F para os contrastes } \\
\hline Imunocastrados $x$ castrados & $1 \times 5$ & $0,065^{\star}$ & $0,001^{*}$ & $0,060 *$ & 0,118 \\
\hline Imunocastrados $x$ castrados & $2 \times 5$ & $0,043^{*}$ & $0,001^{*}$ & $0,025^{*}$ & 0,733 \\
\hline Imunocastrados $x$ castrados & $3 \times 5$ & $0,024^{*}$ & $0,001^{*}$ & $0,014^{*}$ & 0,179 \\
\hline Imunocastrados $\times$ castrados & $4 \times 5$ & $0,066^{*}$ & $0,001^{*}$ & $0,024^{*}$ & 0,297 \\
\hline CV (\%) & - & 3,56 & 2,53 & 7,07 & 25,67 \\
\hline
\end{tabular}

abMédias dos machos imunocastrados seguidas por letras distintas diferem $(p<0,10)$ pelo teste Tukey. *Média dos machos imunocastrados diferem $(p<0,10)$ da média dos machos castrados pelo teste de contrastes.

Fonte: Adaptado de Kiefer et al. (2011). 
da produção (Bruno et al., 2013).

\section{RACTOPAMINA}

Desde que seu uso foi permitido no Brasil, em 1996, o cloridrato de ractopamina tem sido amplamente adotado pelos sistemas intensivos de criação de suínos. Os comprovados benefícios sobre os parâmetros de desempenho no campo e no abatedouro têm dado suporte à sua utilização, que abrange diferentes estratégias que variam em tamanho de dose e dias de consumo. As doses variam de 5 a 10 partes por milhão e a duração de uso, 21 a 28 dias na maioria dos casos (Heck, 2011a).

A ractopamina â-agonista é um ingrediente adicionado à ração capaz de melhorar o crescimento e aumentar a massa magra com pouca mudança na gordura em machos castrados e fêmeas (Rikard-Bell et al., 2009). É um análogo sintético oralmente ativo das catecolaminas, que são hormônios reguladores de vários processos fisiológicos, pois ativam receptores adrenérgicos específicos (Ramos e Silveira, 2001).

O fornecimento de ractopamina aumenta a deposição de tecido magro em todas as categorias sexuais e reduz a deposição de tecido adiposo em machos inteiros e imunocastrados. Além disso, oferece um ótimo meio de maximizar os efeitos da imunocastração e minimizar o aumento gordura, por vezes, observado em machos submetidos a esta técnica (Rikard-Bell et al., 2009).

Conforme descrito por Barbosa et al. (2012), a ractopamina eleva o ganho de peso em marrãs e suínos machos castrados cirurgicamente ou imunologicamente, pesando de 92 a $125 \mathrm{~kg}$. Machos castrados imunologicamente têm melhor resposta de desempenho para a ractopamina, mas com perdas no rendimento de carcaça, características do lombo e espessura de toucinho da barriga.

Em ensaios desenvolvidos por Moraes et al. (2010), foi constatado que a inclusão de 10 ppm de ractopamina na dieta melhora a conversão alimentar dos suínos, independentemente do sexo. A inclusão de ractopamina na dieta pode prejudicar o ganho de peso dos machos imunocastrados e aumentar o ganho de peso dos machos castrados e das fêmeas, porém sem afetar as características quantitativas de carcaça dos suínos.

A imunocastração aumenta o consumo médio diário e o ganho médio diário de peso, especialmente a partir da segunda semana pós-vacinação secundária. Apesar de grande parte do crescimento adicional dos imunocastrados corresponder a tecido adiposo, esse efeito pode ser atenuado com a suplementação dietética de ractopamina (Rikard-Bell et al., 2009).

Rikard-Bell et al. (2009), ao estudarem os efeitos da inclusão ractopamina em dietas para imunocastrados, concluíram que estas duas tecnologias podem ser utilizadas em combinação para melhorar o desempenho de crescimento e a composição de carcaça. Suínos machos imunocastrados suplementados com ractopamina na ração cresceram 30 \% e $15 \%$ a mais que suínos que não receberam este aditivo, respectivamente, aos 17 e aos 31 dias de estudo. Lanferdini et al. (2012) constataram que a ractopamina melhora o peso de abate e de carcaça quente.

Machado et al. (2010) observaram que machos imunocastrados que receberam ractopamina apresentaram maior peso corporal aos 98 dias, porém sem diferir estatisticamente dos castrados convencionalmente e dos machos inteiros, ambos suplementados com ractopamina e dos imunocastrados que não receberam este aditivo. Foi constatado o mesmo comportamento para o ganho de peso diário. Entretanto, tratando-se da conversão alimentar, os imunocastrados suplementados com ractopamina apresentaram melhor resultado.

Após a segunda dose da vacina, a utilização de dietas com ractopamina e maiores níveis de lisina digestível (>1,00 \%) 
e de energia metabolizável (>3300 kcal/kg de ração) garante ganho de peso satisfatório e ótima conversão alimentar (Silva et al., 2011). A resposta à inclusão da ractopamina na dieta dos suínos é influenciada pelos níveis de aminoácidos. Animais que recebem a ractopamina, mas têm baixos níveis de aminoácidos nas dietas, podem apresentar menor desempenho quando comparados aos animais que sequer recebem o aditivo.

Além disso, deve-se considerar a necessidade de estudos que visem à adequação dos níveis nutricionais das dietas contendo ractopamina para a categoria de suínos imunocastrados (Moraes et al., 2010).

\section{CARCAÇA}

O sexo dos suínos é fator determinante do desempenho e das características quantitativas de carcaça. Fêmeas possuem rendimento de carcaça quente superior aos machos imunocastrados, que por sua vez apresentam rendimento superior aos machos castrados. As fêmeas e os machos imunocastrados possuem maior percentual de carne magra em relação aos machos castrados (Moraes et al., 2010).

Segundo Boler et al. (2012), o uso da castração imunológica tardia para controlar o odor sexual dos machos, como alternativa à castração cirúrgica que acontece mais cedo na vida dos suínos, eleva o rendimento dos cortes de suínos machos terminados comparados aos cirurgicamente castrados. A aplicação da imunocastração em suínos machos inteiros não apresenta nenhum efeito prejudicial sobre a qualidade da carne quando comparada à castração cirúrgica. Machos imunocastrados apresentam maiores valores percentuais de carne magra comparados aos cirurgicamente castrados, porém estes valores são menores se comparados aos machos inteiros (Boler et al., 2011).

Santos et al. (2012) afirmam que suínos imunocastrados apresentam desempenho superior, menor espessura de toucinho $e$ maior percentual de carne magra em relação aos castrados.

Estudos conduzidos por Lanferdini et al. (2012) mostraram que imunocastrados têm peso de abate 3,3 \% superior e peso de carcaça fria 1,4 \% inferior ao de machos castrados.

Boler et al.(2012) realizaram testes com a vacina anti-GnRH e observaram que o impacto sobre a qualidade da carne fresca foi mínima. O marmoreio da carne foi menor em imunocastrados do que nos castrados convencionalmente, embora a magnitude da diferença entre essas duas categorias tenha sido pequena.

\section{CONCLUSÃO}

A vacina empregada na imunocastração é capaz de reduzir as concentrações de escatol e androsterona em suínos machos inteiros, diminui a incidência de brigas e tem efeito direto sobre a nutrição destes animais.

O macho imunocastrado é uma categoria que se comporta como macho inteiro no início, e como macho castrado após a aplicação da segunda dose da vacina, conduzindo à necessidade de adequação das estratégias nutricionais e esta nova realidade.

Imunocastrados respondem bem ao aumento dos níveis de lisina na dieta, apresentam maior ganho de peso, maior rendimento de carcaça e de carne magra e diminuição do toucinho.

A ractopamina, um aditivo modificador do metabolismo, tem sido utilizada pelos sistemas intensivos de produção, em associação à castração imunológica, por melhorar o crescimento, aumentar a massa magra e reduzir a deposição de tecido adiposo.

São precisos estudos que definam corretamente as exigências nutricionais do imunocastrado, e que também possam adequar os níveis nutricionais das dietas contendo ractopamina para esta categoria. 


\section{BIBLIOGRAFIA}

Barbosa, C.E.T.; Silva, C.T.C.; Cantarelli, V.S.; Zangeronimo, M.G.; Sousa, R.V.; Garbossa, C.A.P.; Amaral, N.O. and Zeviani, W.M. 2012. Ractopamine in diets for finishing pigs of different sexual categories. Rev Bras Zootecn, 41: 11731179.

Boler, D.D.; Kutzler, L.W.; Meewse, D.M.; King, V.L.; Campion, D.R.; McKeith, F.K. and Killefer, J. 2011. Effects of increasing lysine on carcass composition and cutting yields of immunologically castrated male pigs. J Anim Sci, 89: 2189-2199.

Boler, D.D.; Killefer, J.; Meewse, D.M.; King, V.L.; McKeith, F.K. and Dilger, A.C. 2012. Effects of slaughter time post-second injection on carcass cutting yields and bacon characteristics of immunologically castrated male pigs. J Anim Sci, 90: 334-344.

Bruno, H.V.; Kiefer, C.; Brumatti, R.C.; Santos, A.P.; Rocha, G.C. e Rodrigues, G.P. 2013. Análise técnico-econômica de suínos machos imuno e cirurgicamente castrados. Ciênc Rural, 43: 2063-2069.

Campbell, R.G. and Taverner, M.R. 1988. Genotype and sex effects on therelationship between energy intake and protein deposition in growimg pigs. J Anim Sci, 66: 676-686.

Comissão Européia. 2008. Directiva 2008/120/ 2008/CE do Conselho, de 18 de dezembro de 2008, relativa às normas mínimas de proteção de suínos.

Dunshea, F.R.; Colantoni, C.; Howard, K.; McCauley, I.; Jackson, P.; Long, K.A.; Lopaticki, E.A.; Nugent, J.A.; Simons, J.A.; Walker, J. and Hennessy, D.P. 2001. Vaccination of boars with a $\mathrm{GnRH}$ vaccine (Improvac) eliminates boar taint and increases growth performance. J Anim Sci, 79: 2524-2535.

Eskinazi, S. 2011. Adoçantes e flavorizantes têm papel importante na nutrição de suínos? http://www.porkworld.com.br/artigos/post/ adocantes-e-flavorizantes-tem-papel-importante-na-nutricao-de-suinos (03/12/2012).

Font, M.; Furnols, I. and Oliver, M.A. 1999. Review: Production and comsuption of pork meat with different levels of boar taint. Food Sci Technol Int, 5: 367-375.

Heck, A. 2011a. A revolution in pork production. In:
London Swine Conference - Exploring the future, 11. Proceedings... London Swine Conference. Ontario. pp. 19-26.

Heck, A. 2011b. Imunocastration in swine: a practical approach. In: London Swine Conference - Exploring the future, 11. Proceedings... London Swine Conference. Ontario. pp. 135-142.

Heo, K.; Odle, J.; Han, I.K.; Cho, W.; Seo, S.; van Heugten, E. and Pilkington, D.H. 2000 Dietary Icarnitine improves nitrogen utilization in growing pigs fed low energy, fat-containing diets. $J$ Nutr, 130: 1809-1814.

Kiefer, C.; Donzele, J.L. e Olivera, R.F.M. 2011. Planos nutricionais de lisina digestível para suínos machos imunocastrados em crescimento e terminação. Rev Bras Zootecn, 40: 19551960.

Lanferdini, E.; Lovatto, P.A.; Melchior, R.; Klein, C.C.; Broch. J. e Garcia, G.G. 2012. Características de carcaça e da carne de suínos machos castrados e imunocastrados alimenados com diferentes níveis nutricionais. Ciênc Rural, 42: 2071-2077.

Lawrence, V.J. and Coppack, S.W. 2000. The endocrine function of the fat cell-regulation by the sympathetic nervous system. Horm Metab Res, 32: 453.

Lovatto, P.A.; Lehnen, C.R.; Andretta, I.; Kipper, M. e Demori, A.B. 2010. Nutrição de suínos machos inteiros. In: Congresso Latino americano de Nutrição Animal, 4. Anais... CBNA/AMENA. Estância de São Pedro. pp. 205-214.

Machado, G.S. ; Peroni, L.G. ; Mathur, S.; King, V.L. and Crane, J.P. 2010. Effects of ractopamine hydrochloride on growth performace of barrows, entire boars and boars vaccinated with Improvac ${ }^{\mathrm{TM}}$. International PigVeterinary Society Congress, 21. Proceedings... IPVS. Vancouver. pp. 184.

Martinuzzi, P.A.; Viana, A.N.; Kussler, A. e Cereser, N.D. 2011. Imunocastração em suínos. In: Seminario Interinstitucional de Ensino, Pesquisa e Extensão, 16. Anais... UNICRUZ. Cruz Alta. 4 pp.

Moraes, E.; Kiefer, C. e Silva, I. S. 2010. Ractopamina em dietas para suínos machos imunocastrados, castrados e fêmeas. Ciênc Rural, 40: 409-414. 
Pauly, C.; Spring, P.; O'Doherty, J.V.; Kragten, S.A. and Bee, G. 2009. Growth performance, carcass characteristics and meat quality of grouppenned surgically castrated, immunocastrated (Improvac) and entire male pigs and individually penned entire male pigs. Animal, 3: 1057-1066.

Porolnik, G.V.; Lovatto, P.A.; Rossi, C.A.R.; Lehnen, C.R. e Andretta, I. 2009. Suplementação de aminoácidos para suínos castrados ou inteiros em crescimento e terminação. In: Seminário: Sistemas de Produção Agropecuária - Zootecnia, 3. Anais... Dois Vizinhos. 4 pp.

Ramos, F. e Silveira, M.I.N.D. 2001. Agonistas adrenérgicos ß2 e produção animal: II - Relação estrutura-actividade e farmacocinética. Rev Port Ciênc Vet, 96: 167-175.

Rikard-Bell, C.; Curtis, M.A.; Van Barneveld, R.J.; Mullan, A.C.; Edwards, A.C.; Gannon, N.J.; Henman, D.J.; Hughes, P.E. and Dunshea, F.R. 2009. Ractopamine hydrochloride improves growth performance and carcass composition in immunocastrated boars, intact boars, and glits. J Animal Sci, 87: 3536-3543.

Rossi, C.A.R. 2010. Alimentação de suínos em terminação com dietas contendo ractopamina e extratos cítricos: desempenho, características de carcaça, da carne e produto curado. Ph.D. Thesis Universidade Federal de Santa Maria.

Santos, A.P. 2009. Suínos imunocastrados na suinocultura moderna. www.mca.ufms.br/ producao/seminarios/2009/S0SM.pdf (23/08/ 2012).

Santos, A.P.; Kiefer, C.; Martins, L.P. e Fantini, C.C. 2012. Restrição alimentar para suínos machos castrados e imunocastrados em terminação. Ciênc Rural, 42: 147-153.

Schinckel, A.P.; Li, N.; Preckel, P.V. and Einstein, M. 2003. Development of a model to describe the compositional growth and dietary lysine requirements of pigs fed ractopamine. J Anim Sci, 81: 1106-1119.
Silva, M.A.; Barbarino Júnior, P. e Guastale, S.R. 2011. Recomendações nutricionais para machos inteiros submetidos à imunocastração. In: International Symposium on Nutritional requirements of Poultry and Swine, 3. Proceedings... Universidade Federal de Viçosa. Viçosa. pp. 353-375.

Skrlep, M.; Seegula, B.; Zajec, M.; Kastelic, M.; Kosorok, S.; Fazarinc, G. and Candek-Potokar, M. 2010. Effect of immunocastration (Improvac) in fatting pigs I: growth performance, reproductive organs and malodorous compounds. Slov Vet Res, 47: 57-64.

Thun, R.; Gajewski, G. and Janett, F.F. 2006. Castration in male pigs: techniques and 23 animal welfare issues. J Physiol Pharmacol, 57: 189-194.

Tonietti, A.P. 2008. Avaliações do desempenho zootécnico, qualidade da carcaça e carne em suíno macho inteiro imunocastrado. Dissertation. Escola Superior de Agricultura Luiz de Queiroz. Universidade de São Paulo.

Zaltron, C.M.; Garcia, G.G.; Porolnik, G.V.; Lovato, G.D. e Ceron, M.S. 2009. Suplementação de aminoácidos para suínos castrados e inteiros em crescimento e terminação: custo de alimentação. In: Seminário: Sistemas de Produção Agropecuária - Zootecnia, 3. Anais... Dois Vizinhos. 4 pp.

Zamaratskaia, G.; Rydhmer, L.; Andersson, H.K.; Chen, G.; Lowagie, S.; Andersson, K. and Lundstrom, K. 2008. Long term effec of vaccination against gonadotropin-releasing hormone, using Improvac ${ }^{\mathrm{TM}}$, on hormonal profile and behaviour of male pigs. Anim Reprod Sci, 108: 37-48.

Zuluaga, J.J.E.; Zapata, A.G. e Suescún, J.E.P. 2007. Somatotropina porcina exógena (STp) y su relación com lós aminoácidos de la dieta em cerdos de finalización. Rev Lasallista Invest, 4: 32-36. 